\title{
SCIENTIFIC PREREQUISITES AND METHODICAL BASES FOR THE FORMATION OF TACTICAL OPERATIONS IN CRIMINALISTICS
}

\author{
Shevchuk V.M.
}

The scientific prerequisites and methodical foundations of tactical operations in the forensic investigative activity are studied. It's substantiated that the methodical basis for the formation of tactical operations is the active, system-structural and technological approaches. These approaches are becoming more common in the Criminalistics, significantly expanding the opportunities and prospects for the scientific cognition in this field of knowledge. Guided by the fundamentals of the system-structural approach, it can be asserted that a tactical operation has all the attributes of a systemic formation, it should be considered as a complex real system of active type, realized by specially authorized subjects and directed at solving separate tactical (intermediate) tasks stipulated by investigative (judicial) situations. Tactical operation is considered as a systemic formation of the active type, which has such properties as integrity, structuring, hierarchy, purposefulness, relations and interaction between elements. Successful realization of the technological approach to the solution of these problems assumes the necessity of the development of a peculiar program, regulating the preparation and implementation of a tactical operation. The essence of the technological approach to the formation and implementation of tactical operations is the consistent performance of the system of appropriate actions, taking into account the dynamic structure of the activity on investigation of crimes and judicial supervision behind materials of criminal proceedings. It's used for construction of typical programs of crime investigation and the judicial supervision, typical tactical operations, staging, regularity and is a basis technology of formation of tactical and criminalistic complexes aimed at the decision of separate tactical tasks. The technology of a tactical operation should be developed as a kind of criminalistics technology, derivative from investigative technology, technology of investigative (search) actions, technology for crime investigation and judicial proceeding. Prospective directions for the further researches of the considered problematics are offered.

Keywords: tactical operations, methodology of formation of tactical operations, scientific prerequisites for the formation of tactical operations, tactical operations technology, criminalistic theory of tactical operations.

УДК 343.9(075.8)

B. Н. Терехович, адвокат Коллегии присяжных адвокатов Латвии, доктор права, доцент,

Э. В. Ниманде, доцент кафедры уголовно-правовых наук Латвийского университета, доктор права, доцент

\section{СУЩНОСТЬ КРИМИНАЛИСТИЧЕСКОЙ ТЕХНИКИ}

Рассмотрены проблемные вопросы, касаюшиеся совершенства содержания и логического объема понятия «криминалистическая техника». Представлен развернутый анализ онтологии этого понятия. Определень содержание и логический объем понятия «криминалистическая техника».

(C) Терехович В. Н., Ниманде Э. В., 2017 
Ключевые слова: техническая реальность, техника, расследование преступных деяний, теория криминалистики, криминалистическая техника.

Понятие криминалистической техники традиционно используется на всем протяжении появления и развития системы науки криминалистики. В каждом учебнике по криминалистике авторы выделяют раздел «Криминалистическая техника». Этот раздел криминалистики у всех авторов является начальным в особенной части теории криминалистики, он всегда рассматривается перед объяснением криминалистической тактики и криминалистической методики (методики расследования преступных деяний). Это обстоятельство указывает на исключительное положение криминалистической техники в процессе изложения особенной части теории криминалистики. Однако анализ содержания учебников по криминалистке ${ }^{1}$ позволяет сделать вывод о том, что многие авторы без анализа семантики словосочетания «криминалистическая техника» произвольно определяют различные содержание и логический объем понятия «криминалистическая техника». Это обстоятельство порождает бесплодный, искусственный спор о сущности криминалистики и криминалистической техники в частности. Без ясного определения понятия криминалистической техники, основанного на комплексном анализе ключевого слова «техника» и обозначающего его качество, свойство, принадлежность слова «криминалистическая», невозможно объективно определить и оценить правильность логического объема и содержания понятия «криминалистическая техника». Без оценки правильности логического объема и раскрытия содержания понятия «криминалистическая техника» невозможно включение этого понятия в систему науки криминалистики.

Сложность раскрытия содержания и определения логического объема понятия «криминалистическая техника» кроится в глубинных истоках понятия «техника» и понятия «криминалистический». Без учета исторического опыта использования этих понятий невозможно добиться ясности и обоснованности использования понятия «криминалистическая техника» в системе теории криминалистики, а также в системе академического образования и практики юристов.

Основными вопросами культуры человеческой цивилизации являются вопросы миропорядка, мировоззрения, миропонимания и определения места человека в них. Культурное отношение человека к миропорядку, мировоззрению, миропониманию и осознание себя в них характеризуется тремя взаимосвязанными векторами - разумное, нравственное (этическое) и эсте-

${ }^{1}$ Криминалистика: учебник для вузов/Т. В. Аверьянова, Р. С. Белкин, Ю. Г. Корухов, Е. Р. Россинская. 3-е изд., перераб. и доп. М.: Норма, 2007. С. 128-129; Ищенко Е. П., Топорков А. А. Криминалистика: учебник/под ред. Е. П. Ищенко. М.: ИНФРА-М, 2007. С. 52-53; Криминалистика: учебник/под ред. Т. А. Седовой, А. А. Эксархопуло. СПб.: Лань, 2001. С. 80-417; Криминалистика: учебник/под ред. А. Г. Филиппова. М.: Юриспруденция, 2000. С. 22-23; Яблоков Н. П. Криминалистика. М.: Норма, 2001. С. 78-80 и др. 
тическое. Содержание разумного объяснения миропорядка с необходимостью предполагает использование понятия реальности (действительности). Анализ объема и содержания знания о реальности предполагает мироустройство представлять в виде системы трех миров: мир природы; мир, созданный человеком (вторая природа), т. е. мир, появление и существование которого немыслимо без деятельности человека; внутренний мир человека. Существование каждого из этих миров определено их пространственной и временной протяженностью. Мир природы ограничен вселенной и бесконечностью. Мир, созданный человеком, ограничен временем существования и возможностями практической деятельности человеческой цивилизации. Внутренний мир человека ограничен телом и душой человека, а также сроком его разумной жизни. С учетом этого представления основная классификация наук как общественного опыта в области разумного отношения человека к миропорядку и миропониманию может быть выражена следующим образом:

1. Естествознание (естественные науки) - науки, объектом познания которых является мир природы.

2. Обществознание (социальные, гуманитарные, технические науки) науки, объектом познания которых является мир, созданный обществом людей (вторая природа) и место человека в этом мире.

3. Психология - наука, объектом познания которой является внутренний мир человека.

Мир, созданный человеком, проявляется в социальной, гуманитарной и технической реальностях. Это означает, что мир, созданный человеком (вторая природа), описывается и объясняется понятиями, законами и принципами социальных, гуманитарных и технических наук. Основной особенностью этих наук является то, что это рефлексивные знания, т. е. знания о знаниях. Поэтому объем и объективность такого рода знаний всегда находятся в зависимости от опыта (в широком смысле) самого исследователя и его ценностной ориентации. Объекты мира, созданного человеком, всегда наделены смыслом, т. е. их появление и существование всегда зависит от их ценности (значимости) для человека. Ценностная ориентация исследователя определяет систему критериев значимости исследуемых фактов, что, в свою очередь, служит основанием для оценки установленных фактов с нравственных, эстетических и гуманитарных позиций.

Сложность описания реальности «криминалистическая техника» заключается в том, что эта реальность находится в двух плоскостях измерения - в плоскости технической реальности и в плоскости гуманитарной реальности. Только такое представление о природе «криминалистической техники» позволяет добиться ясности в понимании понятия «криминалистическая техника», поскольку «техника» и «криминалистический» являются соответственно объектами технического и гуманитарного познания. Попытки прямого анализа понятия «криминалистическая техника» всегда будут сопряжены с механистичностью определения понятия «криминалистическая техника», что, в свою очередь, следует признать неэффективным подходом. 
Техника - это основной термин теории технической реальности. Использование этого термина позволяет описать и объяснить способы и виды накопления и передачи человеческого опыта. Начала решения проблемы определения значения термина «техника» мы можем найти в трудах античных философов, в частности, Аристотеля. Античные философы понятие техника (от греч. téchne- - искусство, мастерство) использовали для определения особого рода знания. Противопоставляя téchnē другим родам знания, античные философы указывали, что téchnē это такое знание и способность, такие навыки и умения, которые используются в производстве и конструировании, и которые обеспечивают получение определенных результатов. Такого рода знанию и способностям можно научиться в процессе наблюдения и подражания. В таком виде téchnē занимает среднее положение между опытом (empeiria) и теоретическим знанием (episteme). Важным моментом в объяснении téchnē является то, что téchnē и природа (natura) действуют в основном аналогично, т. е. способ, которым порождается природа, и способ, которым производит вещи téchnē, подобны в том, что посредством чего-то из чего-то создается нечто. Основное отличие téchnē от natura заключается в источнике движения. В natura источник движения находится в самом объекте природы, тогда как téchnē свой источник имеет в мыслящей душе того, кто производит, создает, т. е. в человеке. В téchnē результат создания вначале представляется и воспроизводится в акте человеческого мышления (гипотеза, план, проект, модель и т. п.).

Античные философы понятие téchnē характеризовали двусторонне: в отношении техники к теоретическому знанию и в отношении техники к процессам производства, создания чего-либо. Это позволило Аристотелю сформулировать принципиальную идею о технических навыках людей, разделив природно-образованное и искусственно созданное. Искусственно созданное в отличие от природно-образованного, по мнению Аристотеля, не возникает само по себе, а имеет основу своего бытия в том, что его производит, создает человек (дом строится людьми). Однако почти во всех продуктах человеческого труда присутствуют «следы природы». Задача téchnē состоит именно в том, чтобы достроить то, что природа не может достроить сама. При этом в человеческом сознании возникает образ искусственно создаваемого как результат мышления, т. е. разум и душа делают шаг к техническому изменению, творению мира natura заново. В процессе создания искусственного Аристотель выделял человеческое тело как «вместе родившийся орган», а рука, по мнению Аристотеля, является самым ценным, узкоспециализированным орудием труда, т. е. «инструментом из инструментов». Эту идею и в настоящее время пропагандируют приверженцы антропологических теорий технической реальности.

В Средневековье объяснение téchnē получило христианскую трактовку, в которой использовали два взаимосвязанных понятия - ars и ratio seminalis. Ars - это латинский прямой перевод с греческого téchnē и означало «искусство», «умение», а также место, где можно приобрести знание. Ratio seminalis - это, по мнению средневековых философов, зародышевая сила дальнейшего развития, которая заложена во всех деяниях. 
В Новое время с появлением экспериментального естествознания (Галилей) возникала проблема взаимодействия природно-образованного и искусственно-созданного. Эксперимент, выступая как искусственная техника, одновременно является репрезентантом естественного, природного. Философское осмысление техники в Новом времени наиболее полно выразили Ф. Бэкон (1561-1621) и Р. Декарт (1596-1650). Восприятие природы они выражали через противопоставление субъекта и объекта познания. Причем, по мнению Ф. Бэкона и Р. Декарта, оба эти элемента соответствуют друг другу, а вид природы как лишь пространственно-распространенная материя (res extens) становится возможным только через ее отчетливое разделение думающим субъектом (res cogitans). На этой основе в рационализме разрабатывается концепция подчинения природы человеком, которая в дальнейшем получила конкретизацию в эмпиризме и в идеях Просвещения.

В эпоху Просвещения важным трудом обобщения представлений о téchnē является публикация (1751-1780 гг.) под редакцией Д. Дидро и Ж. Л. Д’Аламбера 35-томного издания «Энциклопедия, или Толковый словарь наук, искусств и ремесел» ${ }^{1}$ В ней впервые определяется триединство «наук, искусств и ремесел». Ремеслам и проблемам техники посвящена половина всего издания, включая одиннадцать томов таблиц. Энциклопедисты Д. Дидро и Ж. Л. Д’Аламбер впервые раскрыли равноправное взаимодействие «ремесел» с наукой, выявив «ремесла» как некую систему, сформулировали связь и взаимодействие систем «ремесла» и науки. Это приблизило наше понимание синтеза рациональности и практического умения, синтеза теории и эксперимента, также выразило идею того, что téchnē обладает своей теоретической и практической частью. В Энциклопедии показано, что теоретической частью téchnē является не что иное, как познание правил téchnēe, не связанным с непосредственным действием, а практической частью téchnē является не более чем привычное и не основанное на размышлениях применение этих правил. Таким образом, без теоретического размышления трудно продвинуть практику вперед, однако, с другой стороны, трудно располагать хорошей теорией без практики. Именно благодаря теориям появляется возможность объяснить и устранить трудности практики.

Дальнейшее философское понимание téchnē нашло отражение в трудах немецкой классической философии (И. Кант, Г. Ф. В. Гегель) ${ }^{2}$. Современные проблемы и перспективы технического развития цивилизации в своих работах отразили О. Шпенглер, Л. Мэмфорд, М. Хайдеггер, Г. Маркузе, К. Ясперс и др. ${ }^{3}$

Важной проблемой современной философской концепции техники является проблема человека, создающего и использующего технику, концеп-

${ }^{1}$ Diderot D., D’Alembert J. Encyclopédie, ou Dictionnaire raisonné des sciences, des arts et des métiers, par une société de gens de letteres. A Paris. 1751-1780.

2 Подробно см.: Котенко В. П. История и философия технической реальности: учеб. пособие для вузов. М.: Академ. проект, Трикста. 2009.

3 Подробно см.: Тавризян Г. М. Философы ХХ века о технике и «технической цивилизации». М.: Рос. полит. энцикл. (РОССПЭН), 2009. 
ция соотношения человека и техники, проблема бытия человека в мире техники. В подходе к решению этих проблем существуют различные традиции и тенденции. Современное представление о téchnē в основном развивается в пределах четырех философских направлений: позитивистская сииентистская философия техники, ее сторонники сосредоточили внимание на анализе логико-методологических проблемах научно-технического знания; критическое направление философии техники, ее представители выдвинули на первый план мировоззренческие, этические и ценностные проблемы техники; антропологическая философия техники, ее представители делают упор на синтезе естественных, технических и общественных наук, вульгарный биологизм и субъективизм в понимании технико-производственной деятельности людей, сводимой к сумме действий натуралистически толкуемого индивида; религиозная философия техники, ее сторонники анализ техники осуществляют на основе религиозной телеологии.

Таким образом, универсального, внеисторического понимания техники не существует. Однако общим в понимании техники является то, что техника представляет собой артефакт (искусственное образование), специально созданный человеком. При этом используются его определенные замыслы, идеи, знаки и опыт. Техника представляет собой своего рода специфический инженерный способ осмысленного использования сил и энергии природы, и создается она на основе естественных наук и технических знаний.

Исходным моментом для современного понимания техники является труд как процесс, совершающийся между человеком и природой, в котором человек своей деятельностью опосредует, регулирует и контролирует обмен веществ между собой и природой. В основе техники лежит использование законов природы. Познав их, человек применяет и использует их посредством техники. Техника - это, прежде всего, средства труда, комплекс вещей, которые человек помещает между собой и предметом труда. К технике, кроме средств труда, относятся все материальные условия, необходимые для того, чтобы процесс производства мог вообще совершиться. Основное назначение техники - это полная или частичная замена производственных функций человека с целью облегчения труда и повышения его производительности. Специализация орудий труда в свою очередь служит технической основой разделения труда.

Современное представление о технике комплексно, т. е. техника всегда представляется в виде технической системы, основными функциями которой являются либо компенсаторная функция, либо функция отражения, либо функция преображения, либо функция трансляции, либо различные сочетания этих функций. Технические системы позволяют преодолеть природные недостатки, ограниченности человека (телесные, чувственные, интеллектуальные). Поэтому практическое значение имеет классификация технических систем, основанием которой является область природных недостатков, ограниченностей человека. Таким образом, можно выделить три основные группы технических систем: телесно-технические системы, которые позволяют преодолеть телесно-мускульные природные ограниченности чело- 
века; сенсорно-технические системь позволяют преодолеть чувственнофизиологические природные ограниченности человека; компьютернотехнические системы позволяют минимизировать информационно-психические природные ограниченности человека. Общим для технических систем является то, что они всегда создаются для удовлетворения каких-либо социальных потребностей. При этом не столь важно, из каких элементов и на каких принципах строится конкретная техническая система. Важно то, что цели ее создания и использования, а также критерии оценки полезности всегда задаются человеком.

Техника не создается и не существует вне деятельности людей. Техника создается человеком осмысленно, с учетом особенностей той области деятельности людей, в которой предусматривается использование данной техники. Поэтому каждая профессия, любая человеческая деятельность имеет свою особую технику. В этом и заключается гуманитарная ${ }^{1}$ составляющая любой техники. Вещь может стать гуманитарной в случае сопряжения с ней человеческих ценностей, свойств, качеств ${ }^{2}$. Гуманитарная составляющая техники раскрывается не в вещно-натуралистической сущности техники, а раскрывается в ее смысле, ее духовности как ценностной сути, которую необходимо понять и истолковать. Таким образом, любое отвлеченное рассуждение о технике без указания на ту область деятельности людей, в пределах которой эта техника создается и используется, всегда носит спекулятивный характер и практического значения не имеет.

С учетом сказанного, технику можно представить себе в виде совокупности технических средств и знаний, используемых в конкретных областях деятельности людей. Это обстоятельство позволяет систематизировать технику, классифицируя ее по областям деятельности людей. Так, выделяют сельскохозяйственную технику, строительно-монтажную технику, военную технику, зубоврачебную технику, оргтехнику, космическую технику, компьютерную технику и т. п. Прилагательные «сельскохозяйственный», «строительно-монтажный», «военный», «компьютерный» и т. п. обозначают качество, свойство, принадлежность конкретного вида техники к той области деятельности людей, в которой создается и используется конкретный вид техники. За основу образования прилагательного всегда берется существительное, обозначающее область создания и применения данного вида техники. Например, космос - космический, война - военный, сельское хозяйство - сельскохозяйственный и т. п. Таким же образом исторически была создана, выделена и обозначена техника, в определяющее название которой была положено название специфической области деятельности и знаний людей - расследование преступных деяний (криминалистика - криминалистический).

1 Гуманитарный (от лат. humanitas - человеческая природа, образованность), т. е. относящийся к человечеству, обществу, бытию и сознанию.

${ }^{2}$ Ильин В. В. Методология социально-гуманитарных наук. Философия соичиальныхх и гуманитарных наук: учеб. пособие для вузов/под общ. ред. С. А. Лебедева. М.: Академ. проект. 2006. С. 127. 
Необходимость создания техники для использования в конкретной области деятельности людей определяется социальной потребностью (заказом). Социальной потребностью создания и использования криминалистической техники явилась потребность в реализации принципа состязательности в уголовном процессе и справедливого урегулирования уголовно-правовых отношений, а именно потребность получения в ходе расследования преступных деяний объективных сведений об обстоятельствах, связанных с совершением преступного деяния, обстоятельствах, исключающих уголовное наказание, обстоятельствах смягчающих или отягчающих уголовную ответственность и обстоятельствах, которые могут повлечь освобождение от уголовной ответственности и наказания. Именно эта потребность (задача) реализуется в области расследования преступных деяний и определяет логический объем понятия криминалистической техники.

Расследование преступных деяний (установление обстоятельств, связанных с расследуемым преступным деянием) составляет предмет деятельности криминалиста ${ }^{1}$. Логика реализации предмета конкретной деятельности людей с необходимостью предусматривает использование специфических методов, разработка которых определяется идеей предмета такой деятельности. Именно идея предмета деятельности криминалиста является определяющей в содержании криминалистической техники. Криминалист, расследуя преступные деяния, воспринимает его как событие, отраженное в материальной действительности в виде совокупности следов предметов и следов процессов ${ }^{2}$. Смысл расследования любого преступного деяния заключается именно в том, что в этом процессе с помощью криминалистической техники ведется целенаправленный поиск следов преступного деяния и устанавливается причинно-следственная связь между совокупностью следов преступного деяния и предметами и процессами, составляющими суть события (преступного деяния), что в дальнейшем позволяет объективно судить о событии преступного деяния и правильно осуществлять уголовно-правовую квалификацию «расследованного» события. Именно для этих целей в криминалистике были разработаны и используются три специальных метода познания: криминалистическая идентификация, криминалистическая диагностика и криминалистическая классификация. Таким образом, содержание понятия криминалистической техники определяется содержанием «технической» реализации трех специальных методов криминалистического познания: криминалистическая идентификация, криминалистическая диагностика и криминалистическая классификация 3.

${ }^{1}$ Криминалист - это специалист в области расследования преступных деяний.

2 Подробно см.: Терехович В. Н., Ниманде Э. В. Сущность объекта познания криминалистики. Библиотека криминалиста. М.: Юрлитинформ, 2013. № 1(6). C. 286-293; Терехович B. Н. Теория криминалистики. Общая часть: монография. Рига, 2015. С. 45-56.

3 Подробно см.: Терехович В. Н., Ниманде Э. В. Сущность криминалистической идентификации. Криминалист первопечатный. Харьков: Апостіль, 2011. № 2. С. 29-39; Их же. Сущность криминалистической диагностики. Там же. 2011. № 3. 
Результатом применения криминалистической техники является обнаружение и исследование (идентификационное, диагностическое, классификационное) материально-фиксированных следов преступного деяния. Поэтому к криминалистической технике относят только такие технические средства, а также знания и навыки применения этих средств, которые научно обоснованы и апробированы на практике. Расследование конкретного преступного деяния - это вид практической деятельности, который не предусматривает применение научно необоснованных и неапробированных на практике средств. Следовательно, криминалистическая техника (как система знания) - это раздел особенной части теории криминалистики, в котором описываются и объясняются закономерности появления материально-фиксированных следов в процессе расследования преступных деяний. Появление материально-фиксированных следов в процессе расследования преступных деяний это предвосхищаемый и ожидаемый результат, поскольку получение такого результата всегда научно обосновано и технически реализуемо, т. е. для обнаружения и исследования материально-фиксированных следов преступных деяний уже разработаны и рекомендуются конкретные технические средства, знания и навыки.

Деятельность людей в области создания и использования техники предусматривает не только получение предвосхищаемых результатов, но и обобщение, обозначение и систематизацию знаний, необходимых для создания и использования данной техники. Только в таком виде умение и навыки создания и использования техники могут быть доступны и приняты научным сообществом. Только в таком виде знания о деятельности по созданию и использованию техники могут передаваться последующим поколениям исследователей, использоваться в академическом, профессиональном образовании и практической деятельности.

Знания, необходимые для создания и использования криминалистической техники, традиционно обобщаются в пределах особенной части теории криминалистики в разделе «Криминалистическая техника». Основой систематизации таких знаний является особенности объектов познания при использовании методов криминалистической идентификации, криминалистической диагностики или криминалистической классификации. Например, в разделе криминалистической техники «Трасология» систематизированы знания, необходимые для осуществления криминалистической идентификации и криминалистической диагностики по отображениям на предметах с относительно устойчивой формой; в разделах криминалистической техники «Почерковедение» и «Фоноскопия» систематизированы знания, необходимые для идентификации человека по материально-фиксированным отображениям его функционально-динамических свойств, соответственно по почерку и по голосу; в разделе криминалистической техники «Криминалистическое оружиеведение» систематизированы знания

С. 8-18; Их же. Сущность криминалистической классификации. Там же. 2012. № 4. С. 19-29; Терехович В. Н. Указ. соч. С. 124-153, 222-267. 
об индивидуальном оружии и следах его применения и т. п. Количество и содержание таких разделов «Криминалистической техники» зависит от теоретической обоснованности научно-технических возможностей криминалистической практики, а также от потребности и возможностей применять такую технику в уголовном правоприменении конкретного государства. Например, в уголовном правоприменении некоторых стран системы общего и смешанного права используется понятие «опасный предмет (орудие)», но не используется понятие оружия (холодного оружия). Следовательно, в этих странах нет практической потребности разрабатывать криминалистическую технику в области криминалистического оружиеведения. Поэтому в процессе обучения криминалистов различных государств содержание учебников по криминалистике в части «Криминалистическая техника» может отличаться.

\section{СУТНІСТЬ КРИМІНАЛІСТИЧНОЇ ТЕХНІКИ}

\section{Терехович В. М., Німанде Е. В.}

Розглянуто проблемні питання, що стосуються вдосконалення змісту й логічного обсягу поняття «криміналістична техніка». Подано розгорнутий аналіз онтології цього поняття. Визначено зміст і логічний обсяг поняття «криміналістична техніка».

Ключові слова: технічна реальність, техніка, розслідування злочинних діянь, теорія криміналістики, криміналістична техніка.

\section{THE ESSENCE OF CRIMINALISTIC TECHNICS}

\section{Terehovich V. N., Nimande E. V.}

Complicated nature of describing reality «criminalistic technics» is based on the situation that this reality is situated in two dimensions - dimension of technical reality and dimension of humanitarian reality. There isn't any universal, not-historic understanding of technics. Starting point for contemporary understanding of technics is work as a process between a human being and the nature during which a human being with his activity mediates, regulates and controls exchanging of substances between him and nature. The base for technics is making use of nature laws. After ascertaining nature laws, human being applies and uses them by means of technics. Technics - it's, first of all, tools of labor, complex of things which a human being puts between himself and the item of work. Contemporary notion about technics is complex, id est, technics is presented in the form of technical system, the main functions of which are compensatory function or reflection function, or transforming function, or transmission function, or different combinations of these functions. Technical systems let to overcome natural shortages, limitations (bodily, sensetive or intellectual) of a human being. Technics is created by people knowingly taking into account peculiarities of the field of activity where it's intended to use this technics. Necessity to create technics for using in concrete field of activity is determined by the social necessity. The logical volume of the criminalistic technics notion is defined by social necessity to get when investigating criminal offence, objective information about circumstances linked with its commitment. The content of the criminalistic technics notion is defined by 
the content of «technical» realization of three special methods during criminalistic cognition: criminalistic identification, criminalistic diagnostics and criminalistic classification. Criminalistic technics (as a system of knowledge) is a branch of the special part of criminalistic theory describing and explaining regularities of emergence of materially fixed traces during investigation of criminal offences. It's for finding and examining concrete technical means, knowledge and skills are already worked out and recommended.

Keywords: technical reality, technics, investigation of criminal offences, theory of criminalistics, criminalistic technics.

УДК 343.98

A. Л. Дудніков, доцент кафедри криміналістики Національного юридичного університету імені Ярослава Мудрого, кандидат юридичних наук, доцент

\section{СПОСІБ ЗЛОЧИНУ У СФЕРІ ЕКОНОМІЧНОЇ ДІЯЛЬНОСТІ ЯК СИСТЕМОУТВОРЮЮЧИЙ ЕЛЕМЕНТ КРИМІНАЛІСТИЧНОЇ ХАРАКТЕРИСТИКИ}

Досліджено проблемні питання криміналістичних взаємозв 'язків способу злочину у сфері економічної діяльності з іншими елементами криміналістичної характеристики. На підставі иього аналізу зроблено висновки щодо місия способу злочину в системі елементів криміналістичної характеристики злочинів у сфері економічної діяльності та значення такого підходу для модернізації й удосконалення методик розслідування.

Ключові слова: криміналістична характеристика злочинів у сфері економічної діяльності, спосіб злочину, криміналістичні ознаки злочину.

Сучасні методики розслідування злочинів базуються на їх криміналістичних характеристиках. Проблемами криміналістичної характеристики злочинів займалося багато вчених-криміналістиів, у тому числі такі відомі, як професори Р. С. Бєлкін, О. Н. Колесніченко, В. О. Коновалова, Г. А. Матусовський та ін. Криміналістична характеристика як джерело відомостей про певні види злочинів виконує інформаційну функцію, являє собою єдину інформаційну систему. Отримання й використання такої інформації можливо шляхом аналізу відомостей, що належать до окремих елементів криміналістичної характеристики певного виду злочинів і встановленню зв'язків між ними. Зазначені елементи пов'язані між собою різними формами кореляційних залежностей та утворюють систему, у структурі якої значення кожного з елементів неоднакове, ураховуючи характер злочину. Аналіз кримінальних проваджень стосовно злочинів у сфері економічної діяльності показує, що значна їх кількість учиняється способами, ознаки яких не завжди очевидні. У таких ситуаціях ключовим елементом є спосіб, його знання й опис у системі криміналістичної характеристики. Це пояснюється також тим, що тут, на відміну від багатьох інших видів злочинів, установлення способу дозволяє порівняно легко й швидко встановити та викрити винних осіб і з'ясувати інші обставини предмета доказування.

(С) Дудніков А. Л., 2017 